IJAHP Article: Toth, Wolfslehner, Vacik /A framework of a comprehensive uncertainty analysis of the Analytic Hierarchy Process methodology in the context of environmental decision making To Be Submitted to the International Symposium of the Analytic Hierarchy Process 2014, Washington D.C., U.S.A.

\title{
A framework of a comprehensive uncertainty analysis of the Analytic Hierarchy Process methodology in the context of environmental decision making
}

\author{
Werner Toth \\ University of Natural Resources and Life Sciences \& Vienna University of Economics \\ and Business \\ Vienna, Austria \\ E-Mail: werner.toth@inode.at \\ Bernhard Wolfslehner \\ European Forest Institute \& University of Natural Resources and Life Sciences \\ Vienna, Austria \\ E-Mail: bernhard.wolfslehner@efi.int \\ Harald Vacik \\ University of Natural Resources and Life Sciences \\ Vienna, Austria \\ E-Mail: harald.vacik@boku.ac.at
}

\begin{abstract}
The paper presents a framework to elaborate uncertainties in the Analytic Hierarchy Process methodology. This is done by a research design that allows the definition of environmental decision making and a systematically and explicitly formulated definition of uncertainty, which embraces a denotation, a categorisation and a quantification of uncertainties. The quantification is conducted by a simulation experiment which uses random matrices as data basis to compute different uncertainty scenarios. Furthermore, a group decision scenario is simulated. Expected conclusions include a deeper understanding of different uncertainties, their combinations and their contribution to the incorporated uncertainty in the computed output priorities. Hence, recommendations regarding environmental decision making processes are formulated. However, limitations may arise due to the fact that randomly generated values may be different to human judgements and to time restrictions that limit the range of simulation experiments.
\end{abstract}

Keywords: uncertainty scenarios, simulation experiment

\section{Introduction}

Since its inception, the original Analytic Hierarchy Process (referred to as AHP) has been extensively used in environmental decision making and natural resource management (Vacik \& Lexer, 2001). Often the final results of an evaluation are still under debate, as the underlying methodology and the related assumption do not allow a sound conclusion (Wolfslehner \& Vacik, 2011). Literature research indicates that in most application 
IJAHP Article: Toth, Wolfslehner, Vacik /A framework of a comprehensive uncertainty analysis of the Analytic Hierarchy Process methodology in the context of environmental decision making To Be Submitted to the International Symposium of the Analytic Hierarchy Process 2014, Washington D.C., U.S.A.

studies the embedded uncertainties in the AHP-methodology are not sufficiently acknowledged (Hung et al., 2009). Hence, the overall goal of this contribution is to foster the understanding of the fundamentals of the AHP-methodology and its incorporated uncertainty in the computed output priorities.

\section{Literature Review}

Literature research reveals a wide range of publications that are concerned with uncertainty issues of the AHP-methodology (Hung et al., 2009; Ozdemir \& Saaty, 2006; Paulson \& Zahir, 1995; Sadiq \& Tesfamariam, 2009; Wolfslehner, Vacik, \& Lexer, 2005).The highlights of four key publications led among others to the motivation of this study (Hung et al., 2009; Ishizaka \& Nemery, 2013; Saaty, 2010; Sadiq \& Tesfamariam, 2009). All of them have in common that they either show a reasonable systematic examination of uncertainties or a more or less explicitly formulated understanding of uncertainty. However, publications that try to include both by elaborating an explicitly formulated framework for the understanding of the impacts of different uncertainties are rare. Moreover, the linkage of such a comprehensive uncertainty framework to a specific field of application is absent.

\section{Hypotheses/Objectives}

The research is organised around the following research questions:

RQ1: Which are the different forms of uncertainties associated with the AHPmethodology?

RQ2: What effect does the combination of the identified uncertainties have on the final alternative ranking in the context of environmental decision making?

RQ3: Is it possible to omit identified uncertainties that lead to a considerable reduction of the overall uncertainty in the context of environmental decision making?

To tackle these research questions the following research design has been elaborated.

\section{Research Design/Methodology}

The research design (see Figure 1 (Belton \& Stewart, 2002; Sadiq \& Tesfamariam, 2009; Walker et al., 2003)) embraces the phases "Problem analysis", "Simulation experiment" and "Synthesis". The phase "Problem analysis" and "Simulation experiment" allow the elaboration of different constituent elements (highlighted with bold boxes). The "Problem analysis" leads for example to the definition of environmental decision making (referred to as EDM) as specific field of application. Furthermore a denotation and categorisation of uncertainties can be derived. Figure 1 shows exemplary uncertainties and their denotations and categorisations in the three categories "Generic location", "Type" and "Nature". The phase "Simulation experiment" includes a quantification of the third dimension of the uncertainty conducted with R. A more detailed description can be found in the following chapter "Data/Model Analysis". Thus, the resulting definition of uncertainty becomes explicit by elaborating three dimensions, namely denotation, categorization and quantification. The final phase "Synthesis" includes an evaluation of the single uncertainties and of the computed uncertainty scenarios. 
IJAHP Article: Toth, Wolfslehner, Vacik /A framework of a comprehensive uncertainty analysis of the Analytic Hierarchy Process methodology in the context of environmental decision making To Be Submitted to the International Symposium of the Analytic Hierarchy Process 2014, Washington D.C., U.S.A.

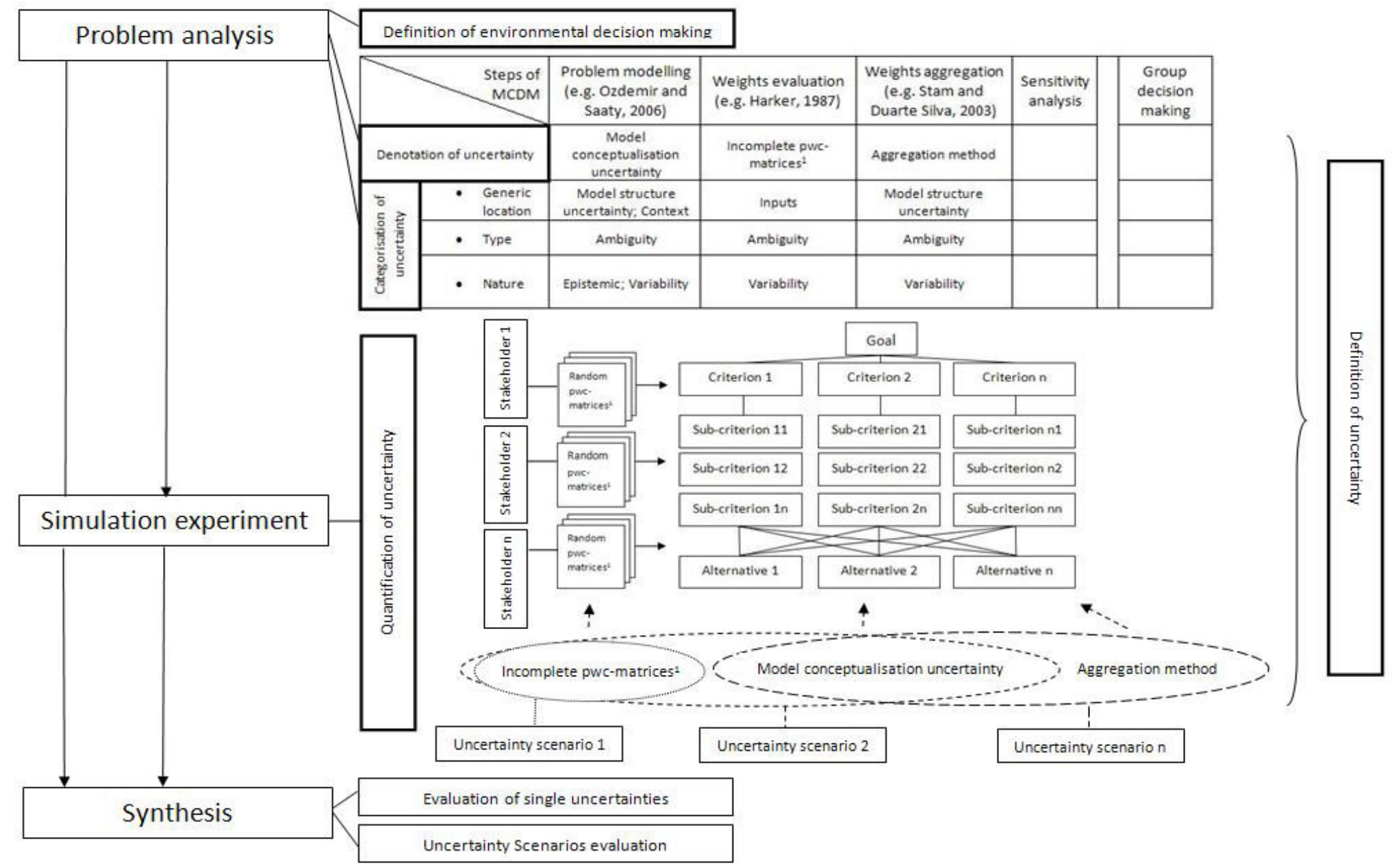

Figure 1 Framework of a comprehensive uncertainty analysis.

${ }^{1}$ Incomplete / Random pairwise comparison matrices. 
IJAHP Article: Toth, Wolfslehner, Vacik /A framework of a comprehensive uncertainty analysis of the Analytic Hierarchy Process methodology in the context of environmental decision making To Be Submitted to the International Symposium of the Analytic Hierarchy Process 2014, Washington D.C., U.S.A.

\section{Data/Model Analysis}

The involved model is going to be basis for the simulation experiment. The modeldevelopment is still in progress, that's why a finalized model structure cannot be presented in the paper proposal. The model is going to be derived from the presented definition of EDM and modified by implementing different categories of uncertainties (see Figure 1). In detail, it is decided to use random matrices as data basis and to compute different uncertainty scenarios by integrating various uncertainties, such as "Model conceptualisation uncertainty", "Incomplete pwc-matrices" or "Aggregation method" at different computing steps of the AHP-methodology. As indicated in Figure 1 a potential uncertainty scenario might be comprised of the single uncertainties "Model conceptualisation uncertainty" and "Incomplete pwc-matrices" (uncertainty scenario 2). Furthermore, the individual judgments are synthesized to a group decision.

\section{Limitations}

Limitations may arise due to the fact that single judgment values of random matrices may in fact be different to human judgments in real world decision processes. Hence, the practical relevance of this study has to be deductively derived from the obtained results. Additionally, time restrictions constrain the simulation of a thorough range of different uncertainty scenarios. It is aimed to cover a broad and sound range of different scenarios.

\section{Conclusions}

The conclusions are going to be derived by answering the research questions RQ1 to RQ3.This leads to the description of the identified uncertainties in the AHP-methodology (see Figure 1) and a deeper understanding of different uncertainties, their combinations and their contribution to the incorporated uncertainty in the computed output priorities. Hence, practical relevant recommendations regarding environmental decision making processes are formulated.

In this context we would propose to conduct real world experiments testing different uncertainty scenarios and not only "separated" uncertainties, such as judgmental uncertainty or the use of different measurement scales.

\section{Key References}

Hung, M.-L., Ma, H.-W., \& Yang, W.-F. (2009). Uncertainty Analysis of the Analytic Hierarchy Process methodology. J. Environ. Eng. Manage., 19(3), 145-154.

Ishizaka, A., \& Nemery, P. (2013). Multi-criteria Decision Analysis: Methods and Software: Wiley.

Saaty, T. L. (2010). Principia Mathematica Decernendi - Mathematical principles of decision making - Generalization of the Analytic Network Process to neural firing and synthesis. Pittsburg: RWS Publications.

Sadiq, R., \& Tesfamariam, S. (2009). Environmental decision-making under uncertainty using intuitionistic fuzzy analytic hierarchy process (IF-AHP). Stochastic Environmental Research and Risk Assessment, 23(1), 75-91. 
IJAHP Article: Toth, Wolfslehner, Vacik /A framework of a comprehensive uncertainty analysis of the Analytic Hierarchy Process methodology in the context of environmental decision making To Be Submitted to the International Symposium of the Analytic Hierarchy Process 2014, Washington D.C., U.S.A.

\section{References}

Belton, V., \& Stewart, T. J. (2002). Multiple Criteria Decision Analysis: An Integrated Approach: Kluwer Academic Publishers.

Harker, P. T. (1987). Incomplete pairwise comparisons in the analytic hierarchy process. Mathematical Modelling, 9(11), 837-848.

Hung, M.-L., Ma, H.-W., \& Yang, W.-F. (2009). Uncertainty Analysis of the Analytic Hierarchy Process methodology. J. Environ. Eng. Manage., 19(3), 145-154.

Ishizaka, A., \& Nemery, P. (2013). Multi-criteria Decision Analysis: Methods and Software: Wiley.

Ozdemir, M. S., \& Saaty, T. L. (2006). The unknown in decision making: What to do about it. European Journal of Operational Research, 174(1), 349-359.

Paulson, D., \& Zahir, S. (1995). Consequences of uncertainty in the analytic hierarchy process: A simulation approach. European Journal of Operational Research, 87(1), 4556.

Saaty, T. L. (2010). Principia Mathematica Decernendi - Mathematical principles of decision making - Generalization of the Analytic Network Process to neural firing and synthesis. Pittsburg: RWS Publications.

Sadiq, R., \& Tesfamariam, S. (2009). Environmental decision-making under uncertainty using intuitionistic fuzzy analytic hierarchy process (IF-AHP). Stochastic Environmental Research and Risk Assessment, 23(1), 75-91.

Stam, A., \& Duarte Silva, A. P. (2003). On multiplicative priority rating methods for the AHP. European Journal of Operational Research, 145(1), 92-108.

Vacik, H., \& Lexer, M. J. (2001). Application of a spatial decision support system in managing the protection forests of Vienna for sustained yield of water resources. Forest Ecology and Management, 143(1-3), 65-76.

Walker, W. E., Harremoës, P., Rotmans, J., van der Sluijs, J. P., van Asselt, M. B. A., Janssen, P., et al. (2003). Defining Uncertainty: A Conceptual Basis for Uncertainty Management in Model-Based Decision Support. Integrated Assessment, 4(1), 5-17.

Wolfslehner, B., \& Vacik, H. (2011). Mapping indicator models: From intuitive problem structuring to quantified decision-making in sustainable forest management. Ecological Indicators, 11(2), 274-283.

Wolfslehner, B., Vacik, H., \& Lexer, M. J. (2005). Application of the analytic network process in multi-criteria analysis of sustainable forest management. Forest Ecology and Management, 207(1-2), 157-170. 